\section{$T_{\text {T }}$ cells for chronic allograft dysfunction}

\section{By Kai-Jye Lou, Staff Writer}

Researchers at the University of Oxford have shown that cellular therapy with ex vivo-expanded human $\mathrm{T}_{\text {reg }}$ cells can prevent a hallmark feature of chronic allograft dysfunction known as transplant arteriosclerosis. ${ }^{1}$ The findings in humanized mice suggest that such therapy could help prolong allograft survival, but the persistence of the immunomodulatory effect in a human system will need to be determined, and validation studies in additional models of transplant dysfunction are needed.

Transplant arteriosclerosis is characterized by the formation of lesions that narrow and occlude the allograft's arteries. This causes ischemia and cell death, which results in the slow, progressive loss of allograft function and eventual allograft failure.

The causal mechanism of chronic graft failure is not well understood, but it is believed to have elements that are different from the mechanism for acute graft failure, which is caused by mismatched human leukocyte antigens (HLAs). Cocktails of immunosuppressive drugs are effective in preventing acute allograft rejection but have shown minimal effects in delaying the progression of chronic graft failure.

In the case of patients with a failing kidney transplant, dialysis remains a treatment option. But short of receiving a new transplant, there are no other long-term solutions for chronic graft failure.

"There really isn't anything available for treating transplantassociated vasculopathies," said Jordan Pober, vice chair of immunobiology for human and translational immunology at Yale University. "If you look at the data in humans, the immunosuppressive drugs, which have worked well at reducing the rate of acute allograft failure, have not been effective in addressing the problem of late graft failure that's often due to transplant vasculopathy. The long-term survival curve of transplanted organs hasn't really budged with the development of these immunosuppressive drugs."

A group at Oxford led by Kathryn Wood, professor of immunology and an associate at the Oxford Stem Cell Institute, is looking to change that with $\mathrm{T}_{\text {reg }}$ cells.

Past studies have suggested that $\mathrm{T}_{\text {reg }}$ cells could help control the immune response in autoimmune diseases and in transplantation., ${ }^{2,3}$ Wood and her team decided to evaluate the ability of different $\mathrm{T}_{\text {reg }}$ cellenriched cell populations to prevent transplant arteriosclerosis.

The team used cell sorting of human donor peripheral blood mononuclear cells (PBMCs) and isolated $\mathrm{T}_{\text {reg }}$ cell-enriched cell populations with over $94 \%$ purity. The researchers then expanded the purified cell populations by more than 600 -fold.
In chimeric mice grafted with a human artery, the $\mathrm{T}_{\text {reg }}$ cell-enriched cell populations reduced transplant-associated arteriosclerosis in the graft compared with nonenriched cell populations. Compared with controls, mice receiving the $\mathrm{T}_{\text {reg }}$ cells also had lower expression of the transplant arteriosclerosis-associated cytokine interferon- $\gamma$ (IFNG; IFN- $\gamma$ ).

The group also showed that a subset of cells with decreased expression of IL-7 receptor (IL7R; CD127) were more potent than the more general $\mathrm{T}_{\text {reg }}$ cell-enriched cell population, which was sorted based on high expression of IL-2 receptor $\alpha$-chain (IL2RA; CD25). High CD25 and low CD127 expression are used in cell sorting as criteria for generating $\mathrm{T}_{\text {reg }}$ cell-enriched cell populations, ${ }^{4}$ but the immunomodulatory capacity of these two cell populations previously had not been compared in vivo.

Results were published in Nature Medicine.

"Regulatory T cells have shown promise for a variety of applications in autoimmunity and transplantation," said Wood, who is corresponding author on the paper. "Our work provides proof of concept in a human in vivo model. We also showed that these two different purified populations of regulatory T cells can vary in their suppressive capacity."

"This is indeed a very interesting preclinical study that shows a potential for $\mathrm{T}_{\text {reg }}$ cell use in clinical medicine, especially the CD127sorted $\mathrm{T}_{\text {reg }}$ cells," said Stephan Ensminger, a professor of experimental cardiac surgery at the University of Erlangen-Nuremberg.

"Right now, allograft recipients are placed on chronic immunosuppression regimens, and clinicians have to regularly titrate drug dosages to make sure the immunosuppressive effect isn't too strong or too weak," noted Qizhi Tang, director of the transplantation research laboratory and an assistant professor in the Department of Surgery at the University of California, San Francisco. " $\mathrm{T}_{\text {reg }}$ cells, on the other hand, might be able to offer more precise control by only suppressing the immune response against the graft."

Tang added that $\mathrm{T}_{\text {reg }}$ cells can persist for up to one year in mice, which suggests that these cells could have a long-term effect. But she also noted that it's unknown how long the cells would persist in humans.

Wood thinks $\mathrm{T}_{\text {reg }}$ cell-based cellular therapies would most likely be used to complement existing immunosuppressive regimens. Immunosuppressive drugs would be used to prevent acute rejection, and $\mathrm{T}_{\text {reg }}$ cells would be added to prevent the formation of the chronic rejectionassociated vasculopathies that gradually kill cells in the graft.

\section{Human data from the mouse}

Because the Oxford researchers evaluated the $\mathrm{T}_{\text {reg }}$ cells in a humanized mouse model, researchers contacted by SciBX think the findings could be more predictive of the clinical experience than if the experiments had been done with regular mice.

"It's great that they're using an in vivo humanized mouse model, and using human immune cells and human grafts as the pure mouse transplant models may not adequately represent graft rejection in humans," said Tang. "The humanized mouse model offers a useful tool to generate in vivo preclinical data before moving into clinical testing."

"The method they used to generate cell populations with regulatory $\mathrm{T}$ cell properties is convincing and the effects that these cell populations 
had in the model are impressive," said Pober. However, he said it still isn't clear how closely the current model mimics the transplant-associated vasculopathies seen in allograft recipients.

"It's not obvious whether the current model is truly a model of the vasculopathies that develop in transplanted organs that lead to chronic graft failure," Pober said. "The lesions they looked at in the model were fairly acute and developed over the course of about a month. But the transplant vasculopathies seen in humans receiving heart or kidney transplants typically take six months to over a year to develop, and histologically they are much less inflammatory than what is observed in the current model."

Pober noted that more can be learned from preclinical studies evaluating human $\mathrm{T}_{\text {reg }}$ cell-based therapy for chronic graft failure, but to do so it would be necessary to develop even better disease models. He said a key question that should be addressed is how long these cells and their immunomodulatory effects persist in a human system.

Ensminger said the effect of immunosuppressive drugs on $\mathrm{T}_{\text {reg }}$ cell-based therapies also will need to be evaluated.

"Current immunosuppressive drugs, such as calcineurin inhibitors, can interfere with the formation, generation and function of $\mathrm{T}_{\text {reg }}$ cells, so I would speculate that these drugs would also interfere with ex vivo-generated and infused $\mathrm{T}_{\text {reg }}$ cells," he told SciBX. "The second question that arises is what the clinical treatment protocol would look like. We would want to know how often these cells would have to be administered and how long their effect would last, especially as transplant arteriosclerosis is a fairly slowprogressing disease."

Tang wanted to know if the quantity of cells being delivered could be reduced by using a population of donor-specific $\mathrm{T}_{\text {reg }}$ cells. "In our own experience in mouse models, donor-specific $\mathrm{T}_{\text {reg }}$ cells are more effective than a polyclonal population. The model they used is one where you could easily test this using human cells."

Wood said her group has now set up the chimeric humanized mouse model for evaluating human skin and islet cell transplants. She told SciBX the next steps are to evaluate the $\mathrm{T}_{\text {reg }}$ cell therapy in combination with immunosuppressive drugs and to identify other cell markers that could help improve the purity and expansion of her team's $\mathrm{T}_{\text {reg }}$ cell-enriched cell populations.

On safety, Wood said the group also is working to identify other cell types that are present in these $\mathrm{T}_{\mathrm{reg}}$ cell-enriched cell populations to see if, in the absence of $\mathrm{T}_{\mathrm{reg}}$ cells, they could contribute to allograft dysfunction. The work described in the paper is unpatented.

Lou, K.-J. SciBX 3(21); doi:10.1038/scibx.2010.634

Published online May 27, 2010

\section{REFERENCES}

1. Nadig, S.N. et al. Nat. Med.; published online May 16, 2010; doi:10.1038/nm.2154 Contact: Kathryn J. Wood, University of Oxford, Oxford, U.K. e-mail: kathryn.wood@nds.ox.ac.uk

2. Long, E. \& Wood, K.J. Transplantation 88,1050-1056 (2009)

3. Tran, D.Q. \& Shevach, E.M. Hum. Immunol. 70, 294-299 (2009)

4. Liu, W. et al. J. Exp. Med. 203,1701-1711 (2006)

\section{COMPANIES AND INSTITUTIONS MENTIONED}

University of California, San Francisco, Calif.

University of Erlangen-Nuremberg, Erlangen, Germany

University of Oxford, Oxford, U.K.

Yale University, New Haven, Conn. 